Cahiers $d u$ MONDE RUSSE

\section{Cahiers du monde russe}

Russie - Empire russe - Union soviétique et États indépendants

$44 / 4 \mid 2003$

Varia

\title{
Vadim Rossman, Russian intellectual antisemitism in the post-communist era
}

\section{Marlène Laruelle}

\section{OpenEdition \\ Journals}

Édition électronique

URL : https://journals.openedition.org/monderusse/4133

DOI : 10.4000/monderusse.4133

ISSN : $1777-5388$

Éditeur

Éditions de l'EHESS

\section{Édition imprimée}

Date de publication : 1 octobre 2003

Pagination : 778-779

ISBN : 2-7132-1833-0

ISSN : $1252-6576$

Référence électronique

Marlène Laruelle, "Vadim Rossman, Russian intellectual antisemitism in the post-communist era », Cahiers du monde russe [En ligne], 44/4 | 2003, mis en ligne le 19 juin 2009, consulté le 03 septembre 2022. URL : http://journals.openedition.org/monderusse/4133 ; DOI : https://doi.org/10.4000/ monderusse. 4133

Ce document a été généré automatiquement le 3 septembre 2022.

Tous droits réservés 


\title{
Vadim Rossman, Russian intellectual antisemitism in the post-communist era
}

\author{
Marlène Laruelle
}

\section{RÉFÉRENCE}

Vadim ROSSMAN, Russian intellectual antisemitism in the post-communist era.

Préface de Sidney Monas. Lincoln, NE-Londres, University of Nebraska Press, Vidal

Sassoon International Center for the Study of Antisemitism, 2002, 309 p.

1 Le livre de Vadim Rossman est consacré aux différents mouvements intellectuels antisémites présents en Russie aujourd'hui. Il cherche à remettre en contexte ces mouvances dans leur histoire spécifiquement russe mais également à rappeler leurs emprunts massifs à des courants similaires présents dans les autres pays européens. Son but est de dépasser les actions antisémites ponctuelles et somme toute limitées que peut connaitre la Russie postsoviétique (graffitis, profanation de cimetières, vandalisme, etc.) et d'en dessiner l'arrièrefond intellectuel. Émerge alors une forme de «climat d'opinion » que l'auteur cherche à mesurer de manière nuancée: il rappelle que l'influence réelle de ces courants sur la population russe est très faible, leur présence au niveau électoral quasiment nulle, mais note également que certaines de ces figures intellectuelles sont très populaires et bien diffusées dans les milieux cultivés. L'auteur part du postulat, classique dans les études concernant les questions identitaires, que la définition de l'ennemi apporte autant, si ce n'est plus, de connaissances sur ce qu'on souhaite pour le peuple russe que sur ce qu'on reproche à son prétendu opposant.

2 Il classe ainsi les mouvances antisémites russes en cinq catégories, chacune proposant une conception spécifique de la nation, définie par la géopolitique (les eurasistes), le religieux (les nationalistes orthodoxes), le social (les nationaux-bolcheviks), le culturel (les néo-slavophiles) ou le racial (les groupuscules nazis et les courants aryanistes et néo- 
païens). Le courant du nationalisme russe le plus ambigu dans son rapport aux Juifs reste l'eurasisme, puisque les pères fondateurs des années 1920 étaient majoritairement philosémites. Les néo-eurasistes, en particulier Aleksandr Dugin, sont bien plus nettement antisémites et pensent l'opposition entre Juifs et Russes comme principielle, de nature. Pourtant, Dugin développe une pensée complexe, affirmant également qu'Israël est le seul pays à avoir réussi à mettre en pratique plusieurs des principes de la « révolution conservatrice » dont il se réclame. Vadim Rossman consacre également un chapitre entier à l'œuvre de Lev N. Gumilev (1912-1992), qui a discrètement fait pénétrer l'antisémitisme dans son historiographie des steppes et son "ethnogénétique » des peuples. Il propose une analyse originale et novatrice de la réception de ces textes gumileviens chez des auteurs de sensibilité nationaliste comme Vadim V. Kožinov.

3 Pour les mouvances national-bolcheviques, qui cherchent à réconcilier le nationalisme russe traditionnel avec l'expérience soviétique, les Juifs sont le symbole du capitalisme et du libéralisme, les responsables de l'effondrement économique de la Russie postsoviétique. Ce courant s'oppose nettement aux néo-slavophiles, pour qui le communisme n'est qu'un corps étranger à la Russie. Se retrouvent chez eux les thématiques classiques de la conspiration judéo-bolchevique (Protocole des Sages de Sion)contre la Russie: les grandes figures politiques de l'URSS, toutes juives, auraient eu pour mission de faire disparaître la Russie et de la dérussifier. Proche des néo-slavophiles, la mouvance de l'orthodoxie nationale se fonde sur l'idée que la conspiration juive n'est pas à fondement économique mais religieux, ayant pour but de détruire le peuple resté le plus chrétien, les Russes. S'appuyant en grande partie sur les œuvres du métropolite de SaintPétersbourg Johann, cette tendance joue la carte du peuple juif déicide, infanticide, régicide, et présente la Russie comme le corps renouvelé du Christ, subissant une deuxième crucifixion. Dans les groupuscules néo-nazis et/ou aryanistes, qui représentent le courant le plus minoritaire du nationalisme russe contemporain, l'opposition entre Russes et Juifs est au contraire pensée sur le mode racial comme celle entre Aryens et Sémites, ces derniers étant censés "polluer» le fonds génétique des Slaves. À la différence des courants précédents, tous farouchement anti-occidentaux, la mouvance aryenne ne cache pas son admiration pour l'expérience allemande des années 1920-1940, et ses références culturelles (occultisme, mythe hyperboréen, etc.) viennent très nettement d'Occident.

Le livre de Vadim Rossman, par une analyse finement menée, permet de mettre en lumière, autour du thème antisémite, la complexité des courants nationalistes russes actuels et les nombreuses contradictions qui les opposent les uns aux autres. Une cartographie des nationalismes contemporains apparaît donc, chaque mouvance accordant une place et un mode de résolution spécifique au soi-disant "problème juif ». L'ouvrage illustre également l'importance d'une connaissance des influences occidentales sur ces penseurs russes, dont les thématiques ne constituent en réalité que les versions russes de propos déjà bien connus en Occident dans toutes leurs variantes, économiques, religieuses ou culturelles. Il resterait alors - mais ce n'était pas là l'objectif premier de l'auteur - à saisir la capacité de diffusion de ces propos dans les milieux académiques et politiques et l'influence réelle de certaines des figures occidentales qui les ont inspirés, par exemple celle du traditionaliste René Guénon. Il semble en effet que la force de ces discours ne réside pas tant dans leur lecture au premier degré, qui n'est effectuée que par de petits groupuscules, que dans les images ambiguës qu'ils diffusent sur une prétendue 
spécificité identitaire russe face à l'Occident, dont le "Juif» ne serait en fait que le symbole le plus visible. 